\title{
LA ELECCIÓN DIRECTA DE LOS ALCALDES: CONTEXTO POLÍTICO Y PROBLEMÁTICA JURÍDICA
}

\author{
JAVIER GARCIAA FERNÁNDEZ \\ CATEDRÁTICO DE DERECHO CONSTITUCIONAL
}




\section{SUMARIO}

1. Antecedentes politicos inmediatos. 2. Antecedentes históricos. 3. El MARCO DEL DERECHO COMPARADO. 4. LOS CARACTERES MÁS SOBRESALIENTES DE LA POLÍTICA MUNICIPAL ESPAÑOLA A COMIENZOS DEL SIGLO XXI. A) DE CARÁCTER POLÍTICO GENERAL. B) DE CARÁCTER POLITICO-INSTITUCIONAL. 5. LA REFORMA DE LAS INSTITUCIONES MUNICIPALES. CONSIDERACIONES GENERALES. 6. LA ELECCIÓN DIRECTA DEL ALCALDE. CONDICIONANTES CONSTITUCIONALES Y MARCO LEGISLATIVO. A) Sistema electoral. B) EficaCia terRitorial del sistema electoral. c) VINCULACIÓN DE LOS CANDIDATOS CON LOS PARTIDOS, COALICIONES Y AGRUPACIONES electorales. D) Posición de los candidatos no Vencedores. Previsiones SOBRE LAS VACANTES SOBREVENIDAS EN EL CARGo DE ALCALDE. 7. LA CONEXIÓN DE LA ELECCIÓN DEL ALCALDE CON LA ELECCIÓN DE LOS RESTANTES MIEMBROS DEL AYUNTAMIENTO. 8. DOS BLOQUES INSTITUCIONALES CONTRAPUESTOS: EL BLOQUE DE GOBIERNo Y EL BLOQUe DE CONTROL. 9. EL ALCALDE Y LA COMISIÓN DE GOBIERNO ANTE LA FUNCIÓN DE GOBIERNO MUNICIPAL. 10. EL CONTROL-SANCIÓN DEL ALCALDE Y LAS POSIBILIDADES DE UNA MOCIÓN DE CENSURA. 11. CONCLUSIONES. 12. REFERENCIAS BIBLIOGRÁFICAS. 


\title{
LA ELECCIÓN DIRECTA DE LOS ALCALDES: CONTEXTO POLÍTICO Y PROBLEMÁTICA JURÍDICA
}

POR

\author{
JAVIER GARCÍA FERNÁNDEZ
}

Catedrático de Derecho Constitucional

\section{ANTECEDENTES POLÍTICOS INMEDIATOS}

A finales de 1998 el Grupo Parlamentario Socialista del Congreso presentó una proposición de ley orgánica que tenía por objeto modificar la elección de los Alcaldes, quienes pasarían a ser elegidos directamente por los electores (B.O.C.G., Congreso de los Diputados, VI legislatura, serie B, núm. 256-I, 7 de diciembre de 1998). Cuando el Congreso de los Diputados fue disuelto esta iniciativa legislativa caducó, si bien el Gobierno y su Grupo Parlamentario en el Congreso habían mostrado su oposición, por lo que difícilmente hubiera podido ser tomada en consideración y, en consecuencia, ser aprobada. La iniciativa era, sin duda, polémica, pero venía a dar respuesta a algunos de los problemas más graves que aquejan a la política local al tiempo que venía a insertarse en una corriente reformadora que ya ha fructificado en países europeos próximos como Portugal e Italia. Cuando aquella proposición de ley es historia, conviene exhumarla para analizar sus antecedentes históricos y comparados así como para analizar los problemas técnico-jurídicos que comportaba. $Y$ es que, en efecto, la pro- 
puesta tenía tal envergadura, suponía un cambio tan radical en la estructura de las Entidades locales que hace aconsejable, ahora que ha perdido toda actualidad política inmediata, analizar ese curioso intento de reforma municipal. Conviene, en primer lugar, hacer un somero repaso a los antecedentes históricos y a los antecedentes que proporciona el Derecho comparado para dilucidar si existía un marco de referencia de cierta solidez en nuestro Derecho histórico y en los sistemas de organización municipal de otros países.

El punto de partida de la proposición de ley está en la misma Constitución. El artículo 140.1 de ésta dejó deliberadamente abierta la forma de elección de Alcaldes, de tal modo que éstos pueden ser elegidos por los Concejales o por los vecinos. El proyecto de Ley de Elecciones Locales de 1978 que elaboró el Gobierno del Presidente Suárez preveía, por su parte, que sería proclamado Alcalde el cabeza de la candidatura más votada pero finalmente el texto aprobado por las Cortes Generales vino a establecer un procedimiento de elección indirecta a través de los Concejales. La Ley Orgánica 5/1985, de 19 de junio, del Régimen Electoral General (en adelante, LOREG), asumió el modelo establecido en la Ley 39/978, de 17 de julio, y en el Capítulo IX de su Titulo IV (artículos 196 a 200) reguló la elección de los Alcaldes por los Concejales y mantuvo igualmente la elección directa de los Alcaldes Pedáneos en las Entidades locales menores, a salvo otro régimen que pudieran establecer las Leyes de las Comunidades que las reconozcan o las instituyan. La LOREG, en cambio, instauró una importante novedad respecto al estatuto de los Alcaldes, al introducir la posibilidad de su destitución a través de la moción de censura constructiva.

El modelo municipal instaurado en 1978 cumplirá pronto veinticinco años. A su vez, el nuevo modelo de régimen local establecido en la Ley 7/1985, de 2 de abril, reguladora de las Bases del Régimen Local (Ley de las Bases del Régimen Local, en adelante), ha alcanzado dieciséis años de existencia. Estos dieciséis años han consolidado un modelo de gobierno local fundado en un marco jurídico más moderno, más participativo y más acorde con los principios constitucionales. Pero al mismo tiempo se percibe que algunas de las disfuncionalidades y de las taras que se fueron arraigando en la vida municipal como consecuencia de cuarenta años de ausencia de democracia (cuando muchos municipios, especialmente rurales, no habían logrado salir todavía del sistema caciquil que se formó durante la Restauración) vuelven a aparecer con formas y expresiones nuevas que dificultan un juego político plenamente democrático, limitan la participación de los 
ciudadanos e inutilizan al Ayuntamiento como centro de imputación de políticas públicas locales, las cuales resultan en la actualidad tanto más necesarias dada la crisis del Estado social. Se puede decir, en suma, que, como toda institución dotada de una dinámica política rica y contradictoria, el municipio español ha sufrido un doble proceso de transformación consistente, de una parte, en una adecuación a los principios políticos y jurídicos que se desprenden de la Constitución, y, de otra parte, en una progresiva pérdida de capacidad de respuesta política a los nuevos requerimientos de participación democrática y de gestión de las demandas sociales que el ciudadano tiende a atribuirle, con independencia incluso de que el ordenamiento no contemple competencias para ese tipo de demandas.

A lo largo de la anterior legislatura, el Gobierno presentó diversas propuestas destinadas a la reforma de las instituciones y de la política municipales, propuestas recogidas en el documento intitulado Medidas para el desarrollo del Gobierno local que preparó la Dirección General para la Administración Local del Ministerio de las Administraciones Públicas. Dicho documento traía causa de otro anterior presentado por el Ministro de Administraciones Públicas al Consejo de Ministros en su reunión de 30 de mayo de 1997 con el título Bases para la negociación del Acuerdo para el Desarrollo del Pacto Local, documento del que el Consejo de Ministros se dio por informado.

El documento titulado Medidas para el desarrollo del Gobierno local contemplaba la reforma de seis Leyes que incidían con mayor o menor alcance en las Entidades Locales y, en lo que concierne a la figura del Alcalde, proponía una nueva distribución de competencias entre éste y el Pleno, una reforma del régimen de adopción de acuerdos para adaptarlo a la nueva distribución de competencias y la introducción de la cuestión de confianza que puede presentar el Alcalde ante el Pleno. Así se reguló finalmente en la Ley 11/1999, de 21 de abril, que fue una de las varias leyes que vinieron a desarrollar los planes de reforma municipal apuntadas en el Pacto Local.

El Partido Socialista Obrero Español, por su parte, elaboró un documento titulado El reto de la autonomía local, debatido en marzo de 1998 por su Consejo Territorial y por su Comité Federal, en el que se suscitaba la elección directa del Alcalde por todos los electores del municipio por considerar que acrecentaría la identificación de los electores con los Alcaldes al tiempo que permitiría conformar mayorías de gobierno más estables. Las razones que condujeron al Partido 
Socialista Obrero Español a propugnar la elección directa del Alcalde por todos los electores eran de naturaleza política, es decir, eran razones fundadas en la búsqueda de una mejor gobernabilidad, de una mayor identificación del Alcalde con los electores $y$, en fin, de un reforzamiento del Ayuntamiento como institución destinada a proporcionar servicios a los ciudadanos.

\section{ANTECEDENTES HISTÓRICOS}

Empezando por el Derecho histórico español, el Alcalde se configuró curiosamente como un cargo de elección directa pero de segundo grado a través de electores-compromisarios previamente elegidos. Ese es el modelo electoral de la Constitución de 1812 desarrollado tempranamente por el Decreto CLXIII, de 23 de mayo de 1812 y por la Instrucción para el gobierno económico-político de las provincias aprobada por Decreto XLV, de 3 de febrero de 1823. Ambas normas apenas tuvieron vigencia, sin embargo, $y$ al restablecerse el régimen constitucional en la minoría de edad de Isabel II se inició un modelo caracterizado por la designación regia del Alcalde de entre los Concejales elegidos por sufragio censitario (Real Decreto de 23 de julio de 1835 para el arreglo provisional de los Ayuntamientos del Reino). A partir de la Ley de Ayuntamientos de 1840 (que no entró en vigor hasta 1843) se confirmará con carácter definitivo el régimen provisional de 1835 y el Alcalde será designado por el Monarca o sus delegados, lo que se reafirma finalmente tanto con la Constitución de 1845 como con la nueva Ley de Ayuntamientos del mismo año. En todo caso, lo que enfrentaba a moderados y progresistas era, no la elección directa, que no se planteaba, sino la elección por parte de los Concejales o la designación regia ya que los progresistas eran conscientes de que tanto la Reina Gobernadora como la Reina titular, que apostaban por el partido moderado, no iban a designar Alcaldes progresistas y que la única posibilidad de acceder al poder municipal era la elección a partir de los Concejales.

Con la revolución de 1868 , sin embargo, se retornará al modelo municipal progresista en punto a la elección de Alcalde pues la nueva Ley Municipal, puesta en vigor por Decreto de 21 de octubre de 1868, introducirá al fin la elección del Alcalde por los Concejales. Es de advertir que, conforme a la exposición de motivos de dicho Decreto, los partidos que destronaron a Isabel II consideraban que la democracia municipal era uno de los objetivos más importantes y urgentes de 
la revolución, de lo que cabe inferir que el procedimiento de elección indirecta del Alcalde era, a sus ojos, el sistema de elección más democrático, quizá porque era el que más se alejaba de una personalización del cargo que identificaban con la oligarquización del poder local. A partir de entonces, la idea de elección del Alcalde por los Concejales sigue siendo un elemento básico del ideario municipal progresista, ideal permanentemente incumplido pues la Ley Municipal de 1877 retorna a la designación regia en los municipios con población superior a seis mil habitantes (que se elevaba a ciento cincuenta mil en el fracasado proyecto de Maura en 1907) y sólo en la Dictadura de Primo de Rivera se fijó la elección como regla en el Estatuto Municipal de 1924 (aunque el elegido no requería necesariamente tener la condición de Concejal) y luego en la Ley Municipal de Cataluña de 1933. Por el contrario, la Ley de Bases de 1935 fue la primera norma legislativa municipal que previó la elección directa en los siguientes términos:

"Los Alcaldes serán siempre elegidos por el pueblo o por el Ayuntamiento. Cuando sean elegidos por el pueblo, deberán reunir las condiciones exigidas para el cargo de Concejal..." (base IX).

Como la Ley de Bases nunca se desarrolló, no es posible saber en qué circunstancias se habría podido proceder a la elección directa del Alcalde. En todo caso conviene advertir dos cuestiones, a saber, que la Constitución de 1931 ya preveía esta doble vía de elección (su artículo 9 contenía un redacción similar al artículo 140.1 de la vigente Constitución) y que la Ley de Bases vinculaba la elección directa del Alcalde a su posible destitución por medio de una votación popular (el llamado recall que tan defendido estaba en América y en Europa en el primer tercio del siglo).

Puede señalarse, como conclusión de estos antecedentes de nuestro Derecho histórico, que la elección directa del Alcalde solamente se plantea en España cuando el nuevo contexto político democrático considera plenamente rechazable el caciquismo, que había sido un elemento estructural del régimen político de la Restauración y, por ende, que la participación pública en la vida municipal es compatible con una cierta personalización de la misma a través de la figura del Alcalde. Dicho en otras palabras, la elección directa del Alcalde se plantea en España cuando se comprueba que la popularidad (y consiguiente personalización) de algunos Alcaldes (Pedro Rico en Madrid, Carles Pi i Sunyer en Barcelona, por poner los ejemplos más relevantes) no es producto de amaños caciquiles sino del apoyo popular expresado a través del sufragio universal. 


\section{EL MARCO DEL DERECHO COMPARADO}

En Derecho comparado, hace falta recorrer también un largo camino para que estos temas se planteen. En el Reino Unido, por ejemplo, la inescrutable e inabarcable maraña de autoridades municipales que se daba hasta casi mediados del siglo XIX se aclaró, dentro de su complejidad, pero sobre la base de que el Alcalde era elegido por los Consejos Municipales, cuyos miembros a su vez eran elegidos por sufragio directo pero censitario (a partir de la Municipal Corporations Act de 1835), sistema que se fue extendiendo a los Consejos de Condado, de Distrito y de Parroquia y finalmente a los London boroughs a través de las sucesivas Local Government Acts de 1888, 1894 y 1899. De esta manera, al comenzar el siglo $X X$ el régimen local británico empezaba a ser algo más uniforme y algo más representativo que un siglo antes, si bien hasta 1919 y 1948, respectivamente, no tuvieron plena capacidad electoral las mujeres ni los "pobres", es decir los ciudadanos que recibían algún tipo de asistencia social de su Parroquia, y hasta 1969 no desapareció totalmente el voto plural, reforma que fue iniciativa del Gobierno laborista de Harold Wilson en medio de importantes presiones conservadoras. Pero lo cierto es que esta maraña de órganos, por un lado, y esta duplicidad de electores, por otro, ha tenido como efecto permanente que en el Reino Unido nadie se haya preocupado de consolidar una Alcaldia fuerte, siendo éste un tema que sigue al margen de las preocupaciones municipales de los británicos: toda la legislación local británica, histórica y presente, es un gran ejemplo de la subalternización del Alcalde en beneficio de los órganos colegiados: su elección anual, la interposición de los Aldermen entre el Alcalde y los Consejeros o, en fin, la elección de segundo grado del antiguo Lord Mayor de Londres solamente por y entre los Aldermen. El Alcalde en el régimen local británico es un órgano secundario, por lo que el procedimiento de su elección carece igualmente de relevancia.

En Alemania, dentro de su pluralidad territorial, se observa desde el siglo XIX una tendencia casi continua que alcanza hasta el nacimiento de la República Federal. La larga y persistente lucha que sostuvo la burguesía urbana desde la Edad Media por dominar en las ciudades frente al poder real y al poder feudal determinó el asentamiento de poderosas instituciones municipales muy poco personalizadas, donde el Alcalde, Burgomaestre o denominación similar era el representante de esas instituciones antes que un cargo fuerte e individualizado. $Y$ ese modelo fue asumido en las reformas municipales prusianas de von Stein (Ordenanza de las Ciudades de 1808), que 
implantará una organización dual (la Asamblea de Diputados con su propio Presidente que elige al Magistrat, que es el órgano ejecutivo colegiado presidido a su vez por el Burgomaestre o denominación similar). Sólo la Ordenanza de las Ciudades de la Provincia del Rhin de 1856 sustituyó al Magistrat colegiado por un Alcalde, pero el cambio se limitó a aquellas provincias prusianas que más influencia francesa habían recibido. Estos antecedentes explican que en el actual sistema municipal alemán, y siempre dentro de una gran variedad de modelos organizativos, ya que el régimen municipal es competencia de los Ländery no del Bund, predomine la elección indirecta del Alcalde por parte de la Asamblea municipal, si bien dentro de esta estructura básica es posible distinguir el modelo denominado "de Alcalde", muy similar a nuestro ordenamiento vigente (de influjo igualmente francés), el modelo "de Magistrat", que responde al modelo tradicional prusiano, y el modelo "de Director», donde la Asamblea elige junto al Alcalde a un Director que es un gerente de amplias atribuciones aunque subordinado al Alcalde. En dos Länder meridionales (Baviera y Baden-Württemberg) encontramos, por contra, un sistema electoral directo para el Alcalde, que es elegido por los electores al mismo tiempo que la Asamblea municipal y que es relativamente tardío, pues se remonta sólo a la segunda mitad del siglo XIX. Este último caso es la única referencia que tenemos en Alemania de elección directa de Alcaldes y hay que señalar que en ambos casos el Alcalde es al mismo tiempo el Presidente de la Asamblea, algo que no ocurre, sin embargo, en el modelo organizativo de Magistrat, si bien su figura adopta más un perfil de gestor administrativo, sometido a la dirección política de la Asamblea, que de líder municipal.

Siguiendo con otro sistema municipal plural, en Estados Unidos encontramos una notable variedad de sistemas electorales del Alcalde, e incluso no existe Alcalde en multitud de municipios. El modelo municipal norteamericano, a pesar de su extrema multiplicidad (se ha dicho que no hay dos municipios norteamericanos organizados de igual manera) respondía a los mismos temores de los que está imbuido el constitucionalismo norteamericano, esto es, el temor a la tiranía encarnada en un órgano ejecutivo fuerte, temor perfectamente expresado en muchos artículos de The Federalist. Y ese temor se expresó en la organización municipal de todos los Estados, fundada en la dicotomía Alcalde-Consejo, ambos elegidos por sufragio directo de los ciudadanos para que ninguno de los dos órganos estuviera revestido de menos legitimidad popular. Este modelo no podía evolucionar de manera similar en toda la Unión, de modo que al final cristalizó en dos tipos de 
organización municipal contrapuestas: Alcalde fuerte/Consejo débil y Alcalde débil/Consejo fuerte. Y, como consecuencia de una transacción, todavía apareció otra variedad: Alcalde fuerte/Consejo débil pero con administrador o gerente que asume todas las funciones administrativas. Este modelo de doble legitimidad popular sigue siendo, en todas sus variantes, el más extendido en Estados Unidos y es un ejemplo muy ilustrativo de cómo la fórmula de la elección directa del Alcalde no constituye en sí misma un modelo orgánico-político cerrado.

Pero al lado de este modelo de organización municipal, en Estados Unidos coexisten otros dos tipos de estructura local que han prescindido del Alcalde. Por un lado, el modelo de Comisión, iniciado a principios de siglo, donde los electores eligen un Gobierno municipal reducido (de cuatro o cinco miembros) que desempeñan todas las funciones locales, tanto administrativas como normativas. Este modelo se extendió muy rápidamente en las dos primeras décadas del sigio, pero luego se estancó y pocas ciudades lo adoptaron posteriormente. Mucho más extendido está el modelo del City Manager que se empezó a implantar también a principios de siglo. En este tipo de organización los ciudadanos eligen al Consejo que, a su vez, contrata a un gerente profesional que dirige la totalidad de los servicios municipales e incluso nombra a los responsables de tales servicios, reservándose el Consejo las competencias de carácter normativo y de programación. A diferencia del modelo de Comisión, cuyo crecimiento está estancado, el de City Manager no deja de extenderse, de modo que si en 1961 había 1796 ciudades que lo habían adoptado, en 1976 ya alcanzaba la cifra de 2414. De esta forma, la profesión de City Manager se ha convertido en una actividad perfectamente regulada, con sus principios deontológicos, sus asociaciones profesionales y su mercado de trabajo bien definido.

Retornando a Europa, en Francia la evolución histórica desde la revolución señala que, salvo períodos muy limitados, el Alcalde ha sido designado por el Monarca o por el Ejecutivo, hasta 1882, en que pasó a ser elegido por el Consejo Municipal. Desde esa fecha y hasta nuestros días, la organización municipal francesa se funda en el modelo Consejo elegido/Alcalde fuerte elegido por el propio Consejo Municipal. De hecho, la evolución del municipalismo francés, tras un primer comienzo dubitativo, ha discurrido a través de dos únicas concepciones: a) la centralizadora, que implantó la Ley de 28 de pluvioso del año VIII, que se extiende durante los dos reinados napoleónicos $y$, ya sin cambio, a partir de la Tercera República, en donde el Alcalde es a la vez representante del poder central y del municipio (lo que justificó durante 
muchas décadas su no elección); b) la más autonomista fundada en la noción del pouvoir municipal que teorizó Henrion de Pansey y que en el fondo se concebía como un bastión de la nobleza rural frente a eventuales invasiones políticas del Parlamento, que tendía a estar dominado por la burguesía urbana. La concepción centralizadora ha ido evolucionando hacia una mayor responsabilización del municipio, pero en la práctica el modelo sigue guardando sus caracteres más profundos. $Y$ en este contexto, se detecta un elemento permanente, la elección del Alcalde por el Consejo Municipal, y otro variable, el sistema electoral del Consejo, cuyo cambio más importante tuvo lugar a partir de la Ley de 19 de noviembre de 1982, que introdujo la atribución de la mitad de los escaños a la lista más votada, ya en primera vuelta ya en segunda. En todo caso, salvo en lejanos y brevísimos periodos históricos, la elección directa del Alcalde por parte de los electores no responde a la tradición política francesa pues, a diferencia de Estados Unidos, no se concibe una legitimación popular de los gobernantes si no es a través de un órgano colegiado representativo (de ahí los insalvables problemas que se producen en las sucesivas cohabitaciones como consecuencia de la mal cerrada reforma constitucional de 1962).

Todo lo contrario que en Portugal, donde la organización municipal se caracteriza por su barroquismo, si bien en los últimos tiempos ha tendido a reforzar la posición política del Presidente de la Cámara. Históricamente, el municipalismo portugués se ha distinguido por dos notas sólo en apariencia incompatibles. Por un lado, una constante preocupación por la descentralización y la autonomía local, que fue desde la década de los treinta del siglo pasado una de las señas de identidad de los liberales y, en general, de la izquierda. Por otro lado, una acumulación de órganos que coexistían dentro de un mismo territorio: en el seno del Concejo coexistían y coexisten varias Parroquias como unidad local descentralizada, durante un tiempo se estableció un delegado del Gobierno en cada municipio que estaba al margen de la organización municipal, y ya en la Constitución republicana de 1911 se distinguía dentro de los órganos municipales los de carácter deliberante y los de carácter ejecutivo. Todos estos rasgos históricos han sido recogidos en la vigente Constitución portuguesa que, tras sus últimas reformas, sigue distinguiendo entre Parroquias y Concejos y entre órganos deliberantes y órganos ejecutivos. Por eso la organización municipal portuguesa, basada fundamentalmente en el Decreto-Ley 188/1984, distingue entre la Cámara, elegida por sufragio universal, la Asamblea, formada por los miembros de la Cámara y los Presidente de las Juntas 
de Parroquia, y el Presidente de la Cámara (Alcalde) que es quien encabeza de la candidatura que más votos ha obtenido en la elección de la Cámara. Como ha escrito la doctrina portuguesa, la dicotomía Cámara/Asamblea difícilmente puede equipararse a la dicotomía órgano ejecutivo/órgano deliberante (a pesar de los términos utilizados en el artículo 241 de la Constitución) ya que mal puede considerarse ejecutivo a un órgano como la Cámara en donde están representados todos los partidos. Quizá para paliar esta confusión y esta duplicación orgánicas, el Decreto-Ley 18/1991 ha venido a reforzar las atribuciones del Alcalde, del que se ha hecho un órgano poderoso y al margen de mayorías inestables al ser el cabeza de la candidatura más votada, con lo que de forma indirecta de elección goza de una legitimidad propia.

Acabamos este recorrido de Derecho comparado con Italia. Este país ha tenido una evolución municipal relativamente próxima a la española, ya que también allí se convirtió en un dogma institucional el modelo centralizador de influjo napoleónico, si bien la progresiva implantación de las autonomías regionales obligó a replantear su pervivencia algunos años antes que en España. Al comenzar la pasada década, la Ley 142, de 8 de junio de 1990, introdujo importantes reformas en la organización municipal italiana (potestad normativa, reordenación de los órganos locales, moción de censura constructiva del Alcalde, establecimiento del Defensor de los Ciudadanos) pero el giro definitivo de la organización municipal se produjo tres años después, con la Ley 81, de 2 de marzo de 1993. Esta última Ley, en efecto, introdujo un cambio intensisímo en la elección del Alcalde $\mathrm{y}$, con ello, una nueva reordenación de las instituciones municipales para acomodarlas a la nueva posición política de aquél. El cambio más importante consistió en la elección directa del Alcalde, para lo cual los candidatos concurren en listas separadas de las que se presentan para elegir a los Consejeros. La elección se prevé a dos vueltas, si bien es elegido en primera vuelta el candidato que haya obtenido el $50 \%$ de los votos más uno, y si nadie obtiene esta cifra sólo pasan a la segunda vuelta los dos candidatos más votados. La legislación italiana ha establecido algunas diferencias según el municipio tenga o no más de quince mil habitantes pero lo importante es que esta elección no se quiere disociar de los partidos y de las opciones ideológicas, de modo que los candidatos han de presentar obligatoriamente su programa y pueden emparentarse con una o varias candidaturas para la elección de Consejeros.

Este cambio tan innovador no podía producirse al margen de las restantes instituciones municipales. La figura política y la posición juridica del Alcalde no cambió en apariencia, pero la transformación 
resultó sumamente intensa porque lo que se reformó fue la Junta Municipal que éste preside y que pasa a ser un órgano de gobierno cuyos miembros ya no son elegidos por el Consejo, sino designados libremente por el Alcalde para asegurar la coherencia del equipo de gobierno municipal. El Consejo, por el contrario, se convierte en órgano normativo y de orientación política. Por otro lado, para asegurar la gobernabilidad del Ayuntamiento vuelve a desaparecer la moción de censura constructiva (se prevé que la pérdida de votaciones no comporta el cese del Alcalde) y en su lugar se configura una moción de censura ordinaria que sin embargo conlleva la disolución del Consejo y la celebración de nuevas elecciones. Finalmente, como otro mecanismo para forzar la gobernabilidad, la reforma de 1993 prevé un premio a la mayoría: la lista de Consejeros más votada obtiene el $60 \%$ de los escaños municipales.

Como conclusión de esta notas de Derecho comparado, se puede señalar que, en los países de cultura municipal continental o anglosajona, la elección directa de Alcalde por parte de los ciudadanos resulta relativamente rara (solamente en la mayor parte de Estados Unidos, en dos Länder alemanes y en Italia) y que tanto en Estados Unidos como en Alemania su implantación es anterior al siglo XX. La causa de esta pobre implantación radica en dos motivos principales: a) la repugnancia del constitucionalismo democrático europeo a hacer coincidir dos legitimidades similares en órganos en cierto modo contrapuestos, donde uno va a controlar políticamente al otro (lo que precisamente explica su implantación en Estados Unidos); b) la resistencia a configurar Alcaldes fuertes frente a órganos colegiados de dirección y hasta ejecución política, como se observa en muchos modelos de organización municipal de Alemania, en el Reino Unido y, hasta hace pocos años, en Portugal. Sin embargo, si la elección directa del Alcalde apenas se ha extendido, sí se observa una tendencia a fortalecer al Alcalde no tanto porque se tienda a un modelo "fuerte" cuanto como a la necesidad de disociar los órganos de gobierno y ejecución y los órganos deliberantes y de orientación política.

\section{LOS CARACTERES MÁS SOBRESALIENTES DE LA POLÍTICA. MUNICIPAL ESPAÑOLA A COMIENZOS DEL SIGLO XXI}

Veintitrés años de política municipal democrática son suficientes para realizar un examen y un balance de los caracteres más sobresalientes que se detectan. El primer elemento, y más positivo, es la rapi- 
dez con que caló en el ciudadano la democracia municipal y el arraigo de la idea de que el municipio es el marco donde se dilucidan muchos problemas y se satisfacen muchas aspiraciones sociales. Esto es tanto más notable cuanto que en España, a diferencia de otros Estados descentralizados, se construyó simultáneamente la democracia municipal y la nueva estructura regional, por lo que hubiera sido entendible que los ciudadanos se desentendieran de la política municipal para dirigir su interés a la nueva política y a las nuevas instituciones autonómicas. No ha sido así y lo acredita la prensa escrita y hablada de alcance local de cualquier región española, fenómeno que no se percibe con tanta intensidad en la prensa de ámbito nacional.

Dicho esto, se percibe no obstante un creciente enrarecimiento de la vida política municipal que en parte expresan los medios de comunicación (mociones de censura a los Alcaldes potenciadas por Concejales tránsfugas más o menos venales, negativas de Alcaldes convocar Plenos para mociones de censura), aunque los elementos más destacables están mucho más soterrados y sugieren quizá un cierto déficit de democracia y de gobernabilidad. Los factores más graves que pueden conducir incluso a un deterioro serio de la democracia municipal se pueden resumir de la siguiente manera:

\section{a) de carácter político general}

El municipio en España ha pasado de ser la célula de la organización territorial del Estado sin otra intermediación que la provincia, a insertarse en una estructura territorial extremadamente compleja donde coexiste con las Comunidades Autónomas (que en parte poseen competencias municipales e incluso pueden dictar Leyes de Régimen Local) y con la Unión Europea cuyas diversas políticas inciden intensísimamente en las competencias municipales. A esto se agrega la crisis fiscal del municipio (que O'Connor mostró en los años setenta sin sospechar el alcance que iba a adquirir veinte años después), que en España se insertó además en la dinámica de descentralización fiscal iniciada a partir de los acuerdos del Partido Popular con los partidos nacionalistas para obtener la primera investidura del Presidente Aznar y que probablemente haya resultado poco beneficiosa para los municipios.

Más concretamente, los factores de carácter general que inciden en el desapoderamiento de los Ayuntamientos como órganos de gestión democrática de los intereses municipales se pueden sintetizar en los siguientes puntos: 
aa) Inmersión del municipio en el entramado institucional de las Comunidades Autónomas

Aunque la Ley de las Bases del Régimen Local se elaboró cuando ya estaban constituidas todas las Comunidades Autónomas, la dinámica política iniciada a partir de la institucionalización de éstas coloca al municipio en una posición muy distinta. En sentido jurídico las Comunidades Autónomas asumen con mayor o menor alcance competencias sobre el régimen local (aunque no todas las han ejercitado) $y$, en muchos ámbitos, el referente de bastantes relaciones jurídicas exteriores del municipio deja de ser la Administración General del Estado para pasar a serlo la Administración autonómica. En sentido político ocurre otro tanto porque los Consejos de Gobierno autonómicos necesitan a la Administración local para consolidar su acción política, lo que no deja de suscitar tensiones cuando Consejo de Gobierno y Ayuntamiento responden a mayorías de partido de carácter distinto.

ab) Incidencia de la Unión Europea en el ejercicio de las competencias municipales

En el entramado de políticas públicas y de regulaciones que desarrolla la Unión Europea hay muchas competencias municipales que resultan afectadas, tanto en el sentido de la superposición de normas que vienen a modular el ejercicio de éstas, como en el sentido de la posibilidad de aplicar fondos comunitarios a las políticas municipales (medio ambiente, vivienda, sanidad, políticas de empleo, obras y servicios municipales). Cierto que junto a la incidencia de estos elementos la propia Unión Europea va ahondando en el principio de subsidiariedad que viene a fortalecer el ámbito competencial privativo del municipio pero ello no empece el hecho cierto de que en el seno de la Unión Europea la política municipal se tiene que desenvolver de manera diferente a como se desarrollaba en el marco del Estado nacional.

\section{ac) Crisis del Estado social}

Con independencia de la visión política que se pueda sostener, es un hecho cierto la crisis del Estado social en su vertiente asistencial. No es que las ideologías liberales lo pongan en cuestión desde planteamientos doctrinales (cuestionamiento doctrinal que incide sin duda en su crisis) sino que han emergido factores demográficos, económicos, 
tributarios y laborales que exigen replantearse su estructura y fines actuales con objeto de poder conservarlo. Esta crisis tiene indudable influjo en la política municipal, tanto porque puede que haya que desplazar al ámbito del municipio la prestación de algunos servicios asistenciales en aras de una mayor eficiencia, cuanto porque el ciudadano va a dirigir a la Administración municipal demandadas que hasta ahora iban destinadas al Estado.

\section{ad) Crisis fiscal del municipio}

Sin entrar en generalizaciones comunes a todos los municipios europeos occidentales y norteamericanos, es posible sostener que a pesar del esfuerzo racionalizador que supuso en su momento la Ley $39 / 1988$, de 28 de diciembre, reguladora de las Haciendas Locales, tanto la participación de los municipios en los tributos estatales como la recaudación de tributos propios empieza a decrecer con los consiguientes efectos restrictivos para el ejercicio de las competencias municipales. Este es un problema general pero tiene también una dimensión social porque este decrecimiento incide de manera desigual en los municipios, de manera que se puede entrar en el círculo vicioso de que los municipios más necesitados de servicios públicos sean también los que posean índices de recaudación mas bajos.

\section{ae) Riesgos de políticas localistas}

No hay que desdeñar, por último, que el municipio puede convertirse en la sede privilegiada de políticas localistas, cuando no insolidarias. Estas politicas pueden ser desarrolladas, en ocasiones, por grupos de interés que han logrado enraizarse en las instituciones municipales por medio de instrumentos clientelares, pero en otras ocasiones es el conjunto de la colectividad municipal el que, con visiones a corto plazo, impulsa actuaciones que resultarán perjudiciales para el municipio a largo plazo (especialmente en el ámbito del medio ambiente, del urbanismo y del Patrimonio Histórico). Ello hace necesario un control que no ha de fundarse en las viejas técnicas de tutela, sino en la adopción de un marco normativo objetivo que dificulte políticas depredadoras o perjudiciales, proporcionando al ciudadano los instrumentos jurídicos necesarios para la defensa del interés colectivo, aunque hay recientes reformas legislativas que apuntan a la dirección contraria. 


\section{b) de carácter político-institucional}

El marco general apuntado en el epígrafe a) viene a señalar los retos generales a los que se enfrentan los municipios españoles después de veinte años de democracia local. Parece obvio que este conjunto de problemas requiere una respuesta política y jurídica a la que han de contribuir el Estado y las Comunidades Autónomas. Pero esta respuesta externa precisa una adecuación interna, en el seno de las propias instituciones municipales. Sin embargo, antes de avanzar remedios jurídico-institucionales, conviene examinar si también en este ámbito interno se detectan disfuncionalidades que vendrían a agravar los problemas generales más arriba señalados. A este respecto, también se pueden apuntar las siguientes cuestiones:

\section{ba) Confusión entre el ámbito ejecutivo y el ámbito deliberante}

Por causas históricas bien conocidas (como se ha apuntado más arriba, el Ayuntamiento, especialmente a partir de la Restauración, fue más la sede de intereses caciquiles homogéneos que una institución plural a donde concurrían diversos intereses) y también por razones teñidas de municipalismo utópico, la ordenación jurídica de los órganos municipales evitó el "parlamentarismo" fundado en un órgano de gobierno o ejecutivo versus un órgano deliberante y de control. Pero este rechazo resultó en realidad ficticio porque la política acabó emergiendo allí donde la Ley había puesto una barrera. Sólo que, al igual que cuando se ponen barreras a los cauces de los ríos, la política desbordó la barrera y acabó inundando los terrenos aledaños. En este caso, la realidad es que en el ámbito municipal existen los partidos políticos, partidos que han obtenido mayor o menor apoyo electoral del ciudadano porque han concurrido con programas y con visiones doctrinales contrapuestas. $Y$ ello tiene como inevitable consecuencia que, desde el primer día que se sientan los Concejales en el salón de plenos de su Casa Consistorial, queda cristalizada una mayoría (que elige al Alcalde) y una minoría que actúa como oposición. Sin embargo, el marco normativo que regula la organización política municipal contempla muy parcialmente esta polarización mayoría (con Alcalde)/oposición pues si bien la Comisión de Gobierno parece responder a un órgano de gobierno o ejecutivo (sus miembros son nombrados y separados libremente por el Alcalde), las atribuciones del Pleno, conforme a lo prevenido en el Texto Refundido de las Disposiciones Legales Vigentes en Materia de Régimen Local, aprobado por 
Real Decreto Legislativo 781/1986, de 18 de abril, y al Reglamento de Organización, Funcionamiento y Régimen Jurídico de las Entidades Locales, aprobado por Real Decreto 2568/1986, de 28 de noviembre, se aproximan también a un órgano de gobierno que, además, puede controlar al Alcalde. Esto ha creado una dinámica política caracterizada por una acumulación de asuntos administrativos y de pura gestión en el orden del día de cada Pleno y, en paralelo, una disminución de las funciones de control politico y de programación y dirección en donde el papel de la oposición se difumina o se desgasta en pequeñas actuaciones de nulo contenido político.

\section{bb) Degradación del ejerciGo de la política institucional en algunos Ayuntamientos}

Aunque quizá en términos cuantitativos sea un tema poco significativo, conviene señalar, porque tiene alguna resonancia en la opinión pública, que se observa algún clima de degradación democrática en la política municipal a causa de actuaciones irregulares de algunos Alcaldes que retrasan injustificadamente la celebración de Plenos municipales, bien por pura desidia, bien para evitar actuaciones críticas de la oposición, bien para evitar una moción de censura lo que es cualitativamente mucho más grave $y$, si duda, delictivo. $Y$ al lado de estas irregularidades hay que señalar igualmente el preocupante fenómeno del "transfuguismo" donde, normalmente por motivos francamente espurios, algunos Concejales abandonan el partido o coalición en cuya candidatura concurrieron a la elección y entregan su voto a la oposición para plantear una moción de censura al Alcalde en ejercicio. $Y$, dentro del fenómeno del transfuguismo, tenemos el del transfuguismo del Alcalde, que en ocasiones abandona el partido con el que fue elegido, se pasa al Grupo Mixto y sigue gobernando el municipio con una mayoría diferente de la que le llevó a la Alcaldía. Igualmente, conectando con lo dicho en el punto b.a), parece necesario recordar que muchos Alcaldes confinan el ejercicio de la oposición por parte de los Grupos minoritarios al punto final de uruegos y preguntas" del orden del día de un Pleno, con lo que la función de control queda reducida a una actividad subalterna de escasa resonancia.

Para acabar este punto hay que mencionar asimismo que en muchos Ayuntamientos está perfectamente indeterminada la posición jurídica de la oposición, la cual carece de un estatuto bien delimitado. El problema no reside, claro está, en el desconocimiento del 
estatuto de Grupo y de Concejal de la oposición (subvenciones, medios materiales y personales) sino en la frecuente denegación de información o de acceso a expedientes administrativos, que son un requisito para poder ejercer una buena función opositora en representación de los ciudadanos que votaron a los partidos o coaliciones minoritarias.

\section{bc) La degradación de la gobernabilidad en el ámbito municipal}

Siendo preocupantes todos estos factores, que restan credibilidad a las instituciones democráticas y dificultan una buena gestión municipal, el problema más profundo que experimentan actualmente las instituciones políticas municipales es la paulatina pérdida de gobernabilidad, fenómeno que no tiene origen jurídico sino político pero al que hay que dar una respuesta jurídica. Como se vio en las elecciones locales y autonómicas de 1995, en las legislativas de 1996 e incluso en las frecuentes encuestas de intención de voto que efectúan entidades públicas y privadas, el comportamiento electoral de los ciudadanos y el propio régimen electoral no propician mayorías sólidas. No resultaría muy erróneo predecir, en consecuencia, que en los próximos años será difícil que se consoliden mayorías municipales que apoyen suficiente y permanentemente a los Alcaldes. Es más, bien por razones "patológicas" (transfuguismo de Concejales o de Alcaldes), bien por razones "naturales" (dispersión del voto) existe un riesgo cierto de Alcaldes que gobiernan en minoría gracias a que la moción de censura es constructiva. Pero este gobierno minoritario tiene efectos muy graves a la hora de aprobar el Presupuesto de la Entidad o a la hora de adoptar acuerdos de importancia social o económica que requieren mayoría absoluta. El resultado son Alcaldes capitidisminuídos, con capacidad de gobierno y de dirección política muy limitada más allá de la mera gestión administrativa (va hay ejemplos en España). En el contexto de desafíos señalado en el epígrafe a), la pérdida de gobernabilidad de un Ayuntamiento constituye, sin exagerar, un drama para los ciudadanos de ese municipio pues, como hemos señalado, el Ayuntamiento cada vez evoluciona más hacia una entidad prestadora de servicios sociales, pero dificílmente puede cumplir esa función si el Alcalde no dispone de una mayoría suficiente con la que diseñar políticas públicas y ejecutarlas adecuadamente. Es más, la percepción que pueda formarse el ciudadano sobre la incapacidad de su Ayuntamiento para ofrecer servicios públicos resta legitimidad no sólo a la Entidad local sino al régimen democrático en su conjunto. 
Podemos concluir este apartado 4 señalando dos ideas centrales que pueden contribuir a entender la posición política de los Ayuntamientos españoles tras más de veinte años de democracia municipal:

1. es una Entidad local cuyo ámbito de atribuciones se enmarca dentro de los inputs que generan la Unión Europa, el Estado y la respectiva Comunidad Autónoma, de tal manera que ha de encontrar su campo competencial conforme al principio de subsidiaridad, pero sin que el principio de autonomía municipal le conduzca a incurrir en actitudes localistas que le distanciarian del marco político general que va configurando el ordenamiento para asegurar el principio de solidaridad interterritorial (artículos 2 y 138 de la Constitución);

2. para dar respuesta a dichos inputs, el Ayuntamiento precisa un marco jurídico-institucional que asegure su gobernabilidad, pero en el presente se detectan factores preocupantes que apuntan a un cierto déficit de gobernabilidad así como a ciertas prácticas que, por causa de la confusión de atribuciones intraorgánicas, desnaturalizan tanto el gobierno como el control municipales.

Para hacer frente a ambos problemas no es descabellado plantear una profunda revisión del ordenamiento jurídico municipal que permita situar al Ayuntamiento en una posición más sólida para dar respuesta a las nuevas demandas a la par que introduce mecanismos institucionales que permitan asegurar su gobernabilidad.

\section{LA REFORMA DE LAS INSTITUCIONES MUNICIPALES. CONSIDERACIONES GENERALES}

Hasta aquí hemos efectuado un conjunto de consideraciones dirigidas a mostrar el entorno jurídico y político en que se sitúan actualmente los Ayuntamientos españoles. Para hacer frente a los riesgos de degradación señalados y para fortalecer a la institución municipal en el complicado marco de competencias yuxtapuestas Unión Europea-Estado-Comunidad Autónoma, parece necesario proceder a una profunda reforma de las instituciones municipales. Ahora bien, en la opción de proceder a dicha reforma, ésta ha de centrarse en la posición política de los órganos del Ayuntamiento en la línea de deslindar con mucha más intensidad la función de gobierno y la función de control y de impulso político, lo que significa reforzar notablemente las atribuciones gubernativas y ejecutivas del Alcalde y de su equipo, reforzando al mismo tiempo la función de dirección y control 
del Pleno. En este punto no hay discrepancias significativas entre la derecha y la izquierda. El tema más complejo que se suscita, sin embargo, dentro de estos mecanismos de reforzamiento de las funciones de gobierno y ejecutivas del Alcalde y de deslinde más nítido de éstas con las de control e impulso atribuidas al Pleno, es la viabilidad jurídica y política de que tales mecanismos se configuren a partir de la elección directa del Alcalde por parte de los electores, así como los cambios subsiguientes a operar en el entramado institucional del Ayuntamiento, y es lo que vamos a examinar a continuación. Es cierto que dentro del Pacto Local y en paralelo a la reforma de LOREG, en 1999 se modificó la Ley de las Bases del Régimen Local (Ley 11/1999, de 21 de abril) para fortalecer al Alcalde mediante una redistribución de competencias entre éste y el Pleno, pero aun siendo positiva no parece que venga a transformar radicalmente la posición político-institucional del Alcalde.

\section{LA ELECCIÓN DIRECTA DEL ALCALDE. CONDICIONANTES CONSTITUCIONALES Y MARCO LEGISLATIVO}

La elección directa del Alcalde por parte de los electores está contemplada, como hemos visto más arriba, en el artículo 140 de la Constitución:

\footnotetext{
«... Los Alcaldes serán elegidos por los Concejales o por los vecinos...".
}

Los términos tan rotundos de este precepto nos evitan efectuar más razonamientos pues queda claro que la Constitución contempla expresamente la elección directa del Alcalde. Dicho esto, es necesario examinar la fuente a la que la Constitución atribuye la determinación de quienes son los electores del Alcalde ya que en este artículo no aparece ninguna norma de remisión.

Dicha remisión aparece ya en el artículo 53.1 de la Constitución que establece la reserva de ley para la regulación de los derechos y libertades recogidos en el Capítulo Segundo del Título Primero, entre los cuales hay que incluir los derechos a participar en los asuntos públicos directamente o por medio de representantes y a acceder a las funciones y cargos públicos (artículo 23). Esta reserva de ley, además, es orgánica conforme al artículo 81 de la propia norma constitucional y se ha efectuado a través de la LOREG, cuyo Capítulo IX del Título IV (artículos 196 a 200) establece el procedimiento de elección del Alcalde. Por consiguiente, son dichos preceptos de la LOREG los que habría que 
reformar si se deseara cambiar el cuerpo electoral que elige al Alcalde en base a la previsión constitucional del artículo 140.

Hay que señalar, por último, que en el ordenamiento vigente esta materia es competencia del Estado. Así lo establece la Disposición Adicional Primera de la Ley Reguladora de las Bases del Régimen Local, que confirma la competencia del Estado para regular la posición jurídica del Alcalde, y lo mismo hace la Disposición Adicional Primera de la LOREG respecto al sistema electoral.

Determinada la legitimidad constitucional y la clase y rango de la fuente que regula la elección directa del Alcalde, es preciso pasar a examinar a continuación el contenido regulatorio que derivaría del cambio de elección. Concretamente, se han de examinar: a) el sistema electoral; b) la eficacia territorial del sistema electoral; c) la vinculación de los candidatos a los partidos, coaliciones o agrupaciones electorales; d) la posición de los candidatos no vencedores; e) las previsiones acerca de una vacante sobrevenida con posterioridad a la elección; f) la conexión de la elección del Alcalde con la elección de los restantes miembros del Ayuntamiento en el tiempo y sus efectos.

\section{a) Sistema electoral}

Por definición, en todo sistema electoral donde hay un solo cargo a cubrir el escrutinio ha de ser mayoritario. Pero, constatada esta primera exigencia, hay que determinar si la elección ha de hacerse a una sola vuelta o a dos vueltas. Esta determinación ha de hacerse buscando la mayor legitimidad del cargo elegido, esto es, que represente al mayor número de electores, lo que está en estrecha relación con el sistema de partidos reinante. Cuando el sistema es bipartidista $o$ al menos con dos partidos dominantes (Reino Unido o Estados Unidos) la legitimidad del cargo electo se asegura simplemente con una elección a una vuelta, pues los terceros partidos suelen alcanzar muy escaso apoyo. Pero allí donde el sistema no es bipartidista, como en España (sobre todo en las Comunidades Autónomas donde existen partidos nacionalistas), la elección a una sola vuelta restaría legitimidad al elegido, pues sería muy difícil que obtuviera la mitad más uno de los votos emitidos. Ello aconsejaría establecer una segunda vuelta para obligar a reagrupar los votos en un número reducido de candidatos que recibirían, de esa manera, un mayor apoyo electoral, reforzándose asi su legitimidad popular. En consecuencia, parecería aconsejable que el sistema electoral que se estableciera fuera mayoritario (por necesidad) y a dos vueltas. 
Determinado este primer elemento del sistema electoral, habría que fijar a continuación cuántos candidatos y con qué requisitos pasarían a la segunda vuelta y si cabrían excepciones a la regla general. Empezando por esto último, conviene apurar el razonamiento que ha conducido a la fijación de las dos vueltas. Si se busca reforzar la legitimidad del candidato electo, convendría contemplar la posibilidad de que éste obtuviera dicha legitimidad en la primera vuelta, mediante un apoyo electoral que rebasase el cincuenta por ciento del electorado. En tal circunstancia, la regla de la segunda vuelta cede cuando un candidato obtiene en la primera la mitad más uno de los votos emitidos, en cuyo caso es proclamado Alcalde. En este punto hay que determinar la base del cómputo, es decir, si la mayoría absoluta ha de calcularse sobre los votos emitidos o sobre el censo electoral. Parecería más aconsejable calcular sobre los votos emitidos, tanto porque el nivel medio de abstención determinaría en la práctica una mayoría absoluta sobredimensionada (quizá un $60 \%$ de los votos emitidos o más), como porque conllevaría una penalización de los electores que han cumplido con su deber, otorgando a los abstencionistas un poder de decisión impropio. Igualmente habría que determinar si ese cómputo hay que hacerlo sobre los votos emitidos o los votos válidos. Aunque en términos cuantitativos la diferencia entre unos u otros es poco relevante, por las antedichas razones parece aconsejable computar sólo los votos válidos, que son lo que realmente expresan una voluntad de elegir Alcalde. En consecuencia, debería ser proclamado Alcalde sin pasar a la segunda vuelta aquel candidato que hubiera obtenido la mitad más uno de los votos válidos emitidos en la primera votación.

A continuación habría que determinar cuántos candidatos deberían pasar a la segunda vuelta y si se debería imponer algún requisito especial para los que pasaran. Con un sistema multipartidista como el que existe en España, si alcanzaran la segunda vuelta varios candidatos estaríamos ante una repetición de la primera, sin apenas cambios en el comportamiento electoral. Por tanto, resulta más congruente que sólo pasen a la segunda vuelta los dos candidatos que más votos obtuvieron. No parece que haya que establecer más requisitos que condicionaran el derecho de voto de los electores.

Finalmente, se plantea el plazo de celebración de la segunda vuelta, que en los sistemas comparados oscila entre una y dos semanas después. En realidad, hay razones para defender tanto uno como otro plazo: no alargar demasiado un proceso electoral, economizar gastos electorales $y$ evitar que las Entidades municipales mantengan una interinidad excesiva versus un período mayor para cerrar alianzas 
y pactos electorales y un plazo más amplio para la proclamación y para el contencioso electoral. En este contexto, ponderando los diversos intereses en juego, quizá cabría inclinarse por la celebración de la segunda vuelta una semana después de la primera.

Esta alteración del sistema electoral ha de reflejarse mediante la consiguiente reforma de los preceptos sustantivos de la LOREG que regulan la elección del Alcalde. Además habría que modificar (o incluir adiciones) los artículos de ésta que inciden en esta doble duplicación de votaciones (campaña electoral, encuestas, papeletas, voto por correspondencia, escrutinio, proclamación de Alcaldes electos, plazo de constitución de las Corporaciones Municipales).

\section{b) Eficacia territorial del sistema electoral}

Un factor extremadamente importante a considerar es la clase de municipios donde implantar la elección directa del Alcalde. En Italia, por ejemplo, es distinto el régimen electoral en los municipios de población superior o inferior a quince mil habitantes. En nuestro ordenamiento, donde las Entidades Locales Menores eligen directamente al Alcalde Pedáneo (artículo 199 de la LOREG), y donde, ya desde un perspectiva sociológica, la personalización de la figura del Alcalde es mucho más intensa, no se encuentran razones para introducir diferencias en función de la mayor o menor población del municipio, al menos en sede de régimen electoral (como se verá más adelante, sí se pueden introducir diferencias en la estructura de la organización municipal). En consecuencia, se puede sostener que el sistema electoral, en lo que atañe al Alcalde, puede responder a un modelo uniforme para toda España.

\section{c) Vinculación de los candidatos con los partidos, coaliciones y agrupaciones electorales}

Adelantando algunas ideas que se desarrollarán en la letra e) de este mismo apartado, hay que advertir que, por las razones que ulteriormente se expondrán, la votación del Alcalde debería realizarse en papeleta separada a la de los Concejales. Se suscita así una disociación de actos de votación que viene a incidir en la vinculación de los candidatos a Alcalde con las candidaturas de Concejales. En realidad, esta vinculación se despliega en varios momentos diferentes: la presenta- 
ción de candidatos, el acto de votación y las operaciones subsiguientes a la proclamación de candidatos que acceden a la segunda vuelta.

En sede teórica es concebible que dos partidos o coaliciones presenten sendas candidaturas a Concejales y acuerden concurrir con un mismo candidato a Alcalde. Así lo contempla la legislación italiana, que llega a una exigencia excesivamente formalista acerca del programa que presentan los candidatos a Alcaldes y los candidatos a Concejales. Es igualmente concebible que una persona independiente de los partidos presente su candidatura y sea apoyada por diversos partidos mediando o no algún pacto pre o post-electoral. Situándonos en otro momento de la elección, no es imposible, en fin, que un elector vote para elegir Alcalde y no a los Concejales, y viceversa. Todas estas posibilidades deberían ser contempladas y resueltas en la reforma de la LOREG.

Empezando por el primer supuesto, cabe recordar que los vigentes artículos 43 a 48 de la LOREG, más el 187 de la misma, han regulado la presentación de candidaturas por parte de partidos, federaciones, coaliciones y agrupaciones de electores, siempre a través de los representantes nombrados al efecto, aunque no se suscitan los casos especiales que pueden concurrir en la elección del Alcalde, a los que acabamos de referirnos. Por ende, habría que prever (y llevar a continuación a la LOREG) las siguientes cuestiones:

ca) Dos o más partidos presentan un mismo candidato a Alcalde

En el ordenamiento vigente la candidatura conjunta de dos partidos se rige bajo la forma de una coalición (artículo 44.2 y 3 de la LOREG) prohibiéndose presentar más de una lista en cada circunscripción. La reforma legislativa habria de optar entre la formación de una coalición exclusivamente para la elección del Alcalde, coexistiendo con dos candidaturas para la elección de los Concejales, o bien permitir que la candidatura individual del Alcalde aparezca apoyada simultáneamente por dos o más partidos, federaciones, coaliciones o agrupaciones electorales. La exigencia de una coalición puede resultar quizá excesivamente formalista y bastaría en consecuencia que en el procedimiento de presentación de candidaturas a Alcalde se previera su apoyo por parte de un conjunto de partidos, federaciones y coaliciones. Incluso sería admisible el apoyo, conjunto, de una agrupación de electores siempre que ésta concurriera también a la elección de Concejales. En cambio, no debería permitirse que se formara una agrupación 
de electores exclusivamente para apoyar la elección de Alcalde y que al propio tiempo el candidato fuera apoyado simultáneamente por otros partidos, y ello a causa del riesgo de distorsión que tendría este tipo de apoyos (un candidato poco seguro del apoyo de su partido podría constituir una agrupación adicional, lo que puede perturbar, distorsionándola, la vida de los partidos políticos). Finalmente, se suscita la duda de si el representante de un partido, federación, coalición o agrupación podría ser simultáneamente el representante de un candidato a Alcalde. Por un lado, se constata que es una elección distinta en cuanto al procedimiento, lo que justificaría un representante diferente. Por otro lado, hay que constatar que se duplicaría el número de personas que los partidos han de dedicar a esta tarea. Quizá cabría una solución equilibrada de modo que se permitiera compatibilizar esta función en los pequeños municipios, por ejemplo en aquellos con censo de población inferior a cinco mil habitantes.

cb) Un candidato independiente es apoyado por uno o varios partidos que simultáneamente presentan candidaturas a Concejales

En este supuesto se suscitan dos dudas: si se debe formalizar o no una coalición $y$, si no es así, quién debe presentar la candidatura del independiente. Respecto a la primera duda entendemos que la exigencia, de Derecho necesario, de formalizar una coalición para apoyar al Alcalde vendría a romper hasta cierto punto la filosofía de la reforma, por lo que debería rechazarse. Despejada esta primera duda emerge a continuación la cuestión de quién debe presentar la candidatura del aspirante a la Alcaldía, dado que en la actualidad el artículo 187 de la LOREG exige, lógicamente, un número de entre $1 \%$ de los inscritos hasta ocho mil firmas para la formación de una agrupación. Aquí cabrían dos posibilidades: o bien el candidato independiente acepta la presentación de uno o de varios partidos, o bien presenta una candidatura con el apoyo de número de firmas que establece el citado artículo 187 de la LOREG, cifra bastante razonable por otra parte.

En el acto de votación habría que decidir si debe haber o no una completa disociación entre uno y otro acto de votación, materializado en la utilización de dos urnas diferentes. En Italia no se produce por completo esta disociación pues incluso se ha previsto el efecto del posible "arrastre" de la candidatura de Alcalde a la de Concejales y viceversa. Lógicamente, en Italia este "arrastre" no es político sino para los supuestos en cierto modo patológicos en que un elector vota 
una sola candidatura y no las dos. Entendemos que en nuestro país esta materia debiera resolverse mediante una disociación completa, es decir, mediante dos urnas separadas en donde cada elector actúa con plena libertad, pues es lo más respetuoso con el principio de no obligatoriedad del voto que inspira nuestro ordenamiento.

Para acabar con este punto c) hay que prever que, tras la proclamación de los dos candidatos que pasan a la segunda vuelta, se produzca o bien un desistimiento de uno de los proclamados, o bien un desistimiento del apoyo recibido por los partidos, federaciones, coaliciones o agrupaciones. El desistimiento de un candidato ya proclamado para pasar a la segunda vuelta ha de tener como efecto ipso iure la proclamación del candidato siguiente, aunque aquí surgen algunas cuestiones como es que el desistimiento se produjera en un plazo tan próximo al día de la votación que el nuevo candidato careciera de tiempo para realizar una mínima campaña: aquí se entrecruzan distintos bienes jurídicos a proteger (derecho del candidato a desistir, elección del Alcalde en plazo, elección disputada) de modo que el que debe merecer más protección es la elección disputada, lo que conlleva establecer una regla sobre duración mínima de la campaña, de tal modo que si el desistimiento se produce en fecha muy próxima al día de la votación, éste deba aplazarse una semana. Por otra parte, si un partido desea dejar de apoyar a un candidato a Alcalde en segunda vuelta, sólo cabe regular como publicidad electoral la información que ese partido o coalición desee difundir informando del hecho, pero sin deducir otros efectos jurídicos.

\section{d) Posición de los candidatos no vencedores}

Esta materia se ha suscitado y resuelto en la legislación italiana y tras la misma aflora un fenómeno nada infrecuente en nuestro sistema electoral municipal, cual es el candidato a Alcalde "quemado", que no desea continuar como cabeza de la oposición municipal. Ante este fenómeno caben tres opciones: no regular ningún supuesto especial; atribuir a este candidato, con algunas condiciones, la condición de Concejal para que pueda encabezar a su Grupo municipal; $y$, en fin, permitir que todos los candidatos a Alcalde puedan compatibilizar esta condición con la cabeza de la candidatura de Concejales. La primera opción es un acicate a la "deserción" de candidatos derrotados, lo que supone una deslegitimación de la política municipal. La segunda opción, que es la que encontramos en el ordenamiento italiano, plantea algunos problemas prácticos, pues habría que resolver si sólo 
adquiere la condición de Concejal el candidato derrotado en la segunda vuelta $u$ otros candidatos derrotados en primera vuelta pero con un porcentaje elevado de votos. Lo primero sería discriminatorio y poco operativo dado el tripartidismo y hasta cuatripartidismo que encontramos en relevantes Ayuntamientos españoles (Madrid, Barcelona, Valencia, Bilbao, Sevilla, etc.). Además, habría que aumentar automáticamente el número de Concejales de la mayoría para seguir manteniendo el mismo equilibrio de mayorias y minorías, lo que puede ser técnicamente complejo. Quizá la solución más simple consista en permitir la compatibilidad entre una candidatura a Alcalde y la cabeza de candidatura de Concejales lo que por otra parte sería un refuerzo interesante de los partidos.

\section{e) Previsiones sobre las vacantes sobrevenidas en el cargo de Alcalde}

Bajo este epigrafe se plantea el tema de los suplentes. No está en la tradición electoral celebrar elecciones parciales sino que, tras una breve experiencia en el Senado, los cargos electivos uninominales van acompañados de un suplente, que evita engorrosas elecciones cuando el cargo queda vacante por cualquier circunstancia. En el caso del Alcalde el problema resulta algo más complejo que en el de un Senador, ya que el suplente de un Senador queda al margen de la Cámara hasta tanto no se produzca el hecho o acto que motiva la sustitución. Pero en el caso de los Ayuntamientos no es concebible un suplente del Alcalde que estuviera al margen. Con todo, parece necesario prever esta figura so pena de tener que acudir a elecciones parciales si sobreviene la vacante. Quizá el procedimiento más simple sea el de atribuir la condición de suplente del Alcalde a uno de los candidatos a Concejal y que con esta condición apareciera en las papeletas, a fin de que el elector valorara las cualidades de dicho candidato que eventualmente podria ocupar la Alcaldía.

\section{LA CONEXIÓN DE LA ELECCIÓN DEL ALCALDE CON LA ELECCIÓN DE LOS RESTANTES MIEMBROS DEL AYUNTAMIENTO}

El contenido de este epígrafe forma parte, como hemos visto más arriba, de la problemática de la elección del Alcalde, y así lo hemos incorporado entre los temas que de la misma se desprenden. 
Sin embargo, sus intensos efectos políticos, su complejidad técnica y la razonable duda acerca de su constitucionalidad hacen aconsejable dedicarle un apartado propio.

La elección directa del Alcalde por parte de todos los vecinos supone, por definición, una votación diferente a la de los Concejales, y ambas votaciones, aunque no muy disociadas en cuanto a los estándares de comportamiento electoral de los ciudadanos, no van exactamente ajustadas. Es más, incluso con una segunda vuelta que ayude a unificar las opciones electorales expresadas por los ciudadanos, en un sistema tripartidista o cuatripartidista como el que hay en muchos municipios españoles, hay mucha probabilidad de que el partido o coalición del Alcalde no obtenga una mayoría absoluta o al menos una mayoría simple holgada. En este contexto, un Alcalde dotado de una legitimidad autónoma del Pleno de la Corporación es, como se ha dicho alguna vez del sistema constitucional norteamericano, una invitación a la lucha. Dado que uno de los objetivos que se persiguen con la elección directa del Alcalde es acrecentar la gobernabilidad del Ayuntamiento, la implantación de un Alcalde fortalecido en su legitimidad democrática pero enfrentado a unas minorías poderosas no aportaría gobernabilidad sino conflictos institucionales.

Para afrontar este riesgo, el nuevo ordenamiento italiano ha optado por una fórmula electoral que ya tenía precedentes en aquel país (la frustrada legge-truffa intentada en 1953 para la Cámara de los Diputados), en virtud de la cual el partido que apoya al Alcalde obtiene una prima electoral consistente en el otorgamiento del $60 \%$ de los Consejeros municipales a la candidatura más votada. Obsérvese que formalmente no se beneficia al partido del Alcalde, sino solamente a la candidatura más votada (lo que significa que si hay dos o más partidos emparentados con el Alcalde, pero no coaligados, sólo uno de esos partidos se llevará esa prima). Pero el resultado de esta fórmula (salvo excepciones realmente raras) es que el Alcalde se ve respaldado por una mayoría sólida que garantiza la gobernabilidad de la institución municipal.

Si se desea implantar la elección directa en nuestro ordenamiento, es necesario afrontar el mismo problema que se ha suscitado en Italia. Un Alcalde cuya legitimidad no procede del Pleno puede ser una "bomba de relojería" si no está apoyado por una mayoría sólida y, desde este punto de vista de la estabilidad institucional, se deben suscribir los razonamientos que llevaron al legislador italiano a implantar dicho sistema. Desde la perspectiva técnico-electoral, por otro lado, el procedimiento no presenta ninguna dificultad, pues se trataría de un 
escrutinio en el que el partido, federación, coalición o agrupación más votada recibe ipso iure el número de escaños que se determina previamente conforme a un determinado porcentaje (que debería ser un $60 \%$ como en Italia pues una cifra menor apenas provocaría mayorías sólidas, sobre todo en los Ayuntamientos pequeños), en tanto que el resto de los escaños se repartiría de conformidad con el sistema proporcional que bien puede ser la vigente regla d'Hondt.

Pero si la técnica de escrutinio apenas presenta dificultades, la duda que emerge no sin justificación es si se puede establecer una prima al partido ganador de unas elecciones. Y las razones ex constitutione que pueden invocarse a favor de esa prima al partido ganador son las siguientes:

a) a diferencia del sistema electoral de las Cortes Generales y de las Asambleas Legislativas de las Comunidades Autónomas antaño denominadas de primer grado (artículos 68 a 70 y 152.1 de la Constitución), el sistema electoral municipal no contiene ningún elemento constitucionalizado (salvo el más que evidente sufragio universal, libre, directo y secreto cuya referencia incluso sobraba en el artículo 140). EI legislador ordinario goza de un margen regulador mucho más amplio que permitiría, incluso, adoptar un sistema mayoritario para la formación de los Ayuntamientos;

b) un valor ínsito en el telos de la ordenación electoral de los Ayuntamientos es la gobernabilidad a tenor de lo expresado en el artículo 140 de la Constitución:

"... Su gobierno y administración corresponde a sus respectivos Ayuntamientos...",

dándose la significativa circunstancia de que las Cortes se definen por su carácter representativo y de que las Diputaciones Provinciales también participan de esta representatividad (artículo 141.2) pero el constituyente no consideró necesario predicarla de los Ayuntamientos. ¿Acaso por no considerarlos representativos de los vecinos? En absoluto. Si así fuera no se hubiera fijado la elección por sufragio universal. Lo que la Constitución ha venido a destacar es, más allá del carácter democrático y representativo de los Ayuntamientos, su naturaleza gubernativa, esto es, de órgano de gestión de los intereses municipales. Cabe sostener, por ende, que el valor "gobernabilidad" en las Entidades municipales es un valor que desplaza y se superpone, sin anularlos, a otros valores como la pura representatividad proporcional y ello explica que las principales sentencias constitucionales sobre el principio de autonomía municipal (sentencias 4/1981, de 2 de febrero; 
32/1981, de 28 de julio; 27/1987, de 27 de febrero, entre otras; en algún obiter dicta de las sentencias 142/1988, de 12 de julio, o 187/1988, de 17 de octubre) remachen la conexión de la autonomía con la gestión de los respectivos intereses.

La conclusión a que se llega es que el valor gobernabilidad, que la Constitución aplica a los Ayuntamientos con un alcance y una rotundidad explícitos que no utiliza para otros órganos o entidades, constituye un mandato al legislador ordinario para que ponga en aplicación cuantos instrumentos sean necesarios para asegurar su vigencia siempre, claro está, que no se quiebren o se limiten otros principios o valores de naturaleza democrática. En consecuencia, si para garantizar el valor gobernabilidad en sede municipal el legislador considerara necesario establecer una prima de escaños en favor de la candidatura más votada, la legitimidad constitucional de esta medida podría predicarse siempre que fuera acompañada de otras garantías que asegurasen el principio democrático, la participación y el pluralismo.

A su vez, para asegurar el principio democrático, la participación y el pluralismo habría que contrarrestar la prima de escaños con un modelo proporcional de reparto de los escaños restantes acompañado, en sede de Ley de Régimen Local, de una atribución de competencias al Pleno que mantuviera la recognoscibilidad de la posición de este órgano como centro de control político y de impulso de políticas y servicios 1 .

Frente a la posible invocación de la quiebra del principio de igualdad, conviene recordar que, en el ámbito electoral, la igualdad se configura como punto de partida, es decir, al ejercitar el ciudadano su derecho, como una posición igual ante el electorado para que éste pueda ejercitar su libertad de elección, y que el ejercicio de esta libertad no se vea enervado ni la igualdad menoscabada por la atribución desigual de Concejales a los diversos partidos concurrentes siempre que la atribución final no resulte desproporcionada. Ello explica la legitimidad constitucional de los utopes" porcentuales para acceder al reparto de escaños que contienen tanto la LOREG [artículos 163.1.a) y $180]$ como las leyes electorales autonómicas.

Hay que recordar asimismo que podría invocarse la exigencia constitucional de sufragio igual (artículo 140) como argumento contra-

1 Exactamente lo contrario que ha hecho la Ley 11/1999, de 21 de abril, al reformar los artículos 20 a 23 de la Ley de las Bases del Régimen Local y desplazar más poder político desde el Pleno hasta el Alcalde. 
rio a la prima de Concejales para el partido vencedor, pues podría aducirse que el voto al vencedor vale más que el voto a los restantes partidos. A este respecto hay que retrotraerse a la historia comparada para recordar que el sufragio igual se establece y se garantiza como reacción frente al voto doble que existía, por ejemplo, en el Reino Unido hasta hace unas pocas décadas o al que estaba vigente en Prusia en favor de los junkers, es decir que, en abstracto, el voto de cada elector debe tener los mismos efectos electorales.

\section{DOS BLOQUES INSTITUCIONALES CONTRAPUESTOS: EL BLOQUE DE GOBIERNO Y EL BLOQUE DE CONTROL}

Si llegara a reformarse la LOREG para establecer la elección directa del Alcalde, el cambio normativo no podría quedar limitado al sistema electoral, pues nos encontraríamos (otra vez la «invitación a la luchan) con un Alcalde reforzado e incluso con una mayoría del $60 \%$ de Concejales que abriría el paso, en algunos casos, a un ejercicio más autoritario de gobierno municipal y, en otras ocasiones, a un Pleno que se impondría al Alcalde y hasta lo suplantaría a pesar del origen popular directo de éste. La elección directa del Alcalde ha de ir imprescindiblemente vinculada a una reforma general de las instituciones municipales de modo que queden delimitados dos «bloques» o ámbitos institucionales configurados en torno a la función de gobierno y gestión y a la función de impulso político y control. Ambos bloques no pueden ni deben constituir el radio de acción de la mayoría y de la oposición, respectivamente, no ya por razones cuantitativas (no todos los Concejales de la mayoría deben ostentar responsabilidades de gobierno municipal), sino porque la mayoría debe concurrir también a la función de control y de impulso políticos, pues esta función no sirve solamente para hacer oposición sino también para reforzar, legitimar y hasta popularizar al equipo de gobierno que preside el Alcalde. Este modelo tiende, a primera vista, aproximarse al parlamentarismo clásico pero aunque funcionalmente se le aproxime, el ámbito de los principios subyacentes en la práctica municipal es muy diferente porque la función de gobierno y de administración que el artículo 140 de la Constitución atribuye a los Ayuntamientos hace que las atribuciones del Pleno se aproximen más a la gestión que a la legislación y al control que la Constitución atribuye a las Cortes Generales.

En el ordenamiento vigente, la organización municipal se basa en una distribución tripartita de funciones, de manera que el Alcalde 
ocupa una posición de órgano externo, representativo y relacional al tiempo que ejerce la jefatura superior de personal y desempeña funciones sancionadoras y contractuales [artículo 21 de las Ley de las Bases del Régimen Local y artículo 24 del Texto Refundido de las Disposiciones Legales Vigentes en materia de Régimen Local, aprobado por Real Decreto Legislativo 781/1986, de 18 de abril (Texto Refundido a partir de ahora)]. Frente al Alcalde, el Pleno dispone de más atribuciones normativas que éste, más las funciones de control y fiscalización, pero también tiene atribuidas funciones de mera gestión (artículo 22 de la Ley de las Bases del Régimen Local y artículo 23 del Texto Refundido). Y la Comisión de Gobierno, que sólo existe de Derecho necesario en los municipios de población superior a cinco mil habitantes, no pasa de ser un órgano de imputación de delegaciones conforme al libre arbitrio del Alcalde (artículo 23 de la Ley de las Bases del Régimen Local). La Ley 11/1999, de 21 de abril, ha desplazado importantes competencias desde el Pleno hasta el Alcalde (gestión económica, empleo público, contratos y concesiones, adquisición de bienes y servicios, etc.), pero este aumento de poderes no fortalece la legitimidad del Alcalde en caso de crisis de transfuguismo.

Esta estructura orgánica, aun reformada, no sólo es incompatible con un Alcalde elegido por sufragio universal. Es en la actualidad ineficiente porque entrecruza funciones de mera gestión y funciones normativas que se reparten, no sin algún capricho, entre el Pleno y el Alcalde cuya acción se prolonga, más o menos claramente, a través de las funciones vicarias de la Comisión de Gobierno. Y mientras tanto la función de control se diluye, lo que perjudica tanto a la oposición como a la mayoría.

Por el contrario, la nueva posición del Alcalde requiere configurar dos bloque funcionales de los que se desprendería la correspondiente estructura orgánica. El primer bloque ha de responder a funciones de control, deliberación e impulso político y, con alcance más restringido, normativo. Estaría formado por las funciones de:

- control político (mociones, preguntas, petición de documentación);

- acuerdos sobre alteración y distribución del termino municipal y planeamiento conforme a la legislación del suelo;

- normas orgánicas y procedimentales;

- tributos y presupuestos;

- normas sobre personal, contratos y bienes;

- impulso político (planes y programas de acción política). 
Este bloque funcional ha de atribuirse al Pleno del Ayuntamiento y trae causa de las atribuciones contempladas en el artículo 22.2 de la Ley de las Bases del Régimen Local pero depurándolas de todo contenido gestor o ejecutivo.

Frente a este bloque se configura el bloque funcional de gobierno, ejecución y gestión, que recogería básicamente el contenido del reformado artículo 21 de la Ley de las Bases del Régimen Local más lo previsto en los artículos 23 y 24 del Texto Refundido (nótese que este artículo 23 es actualmente atribución del Pleno pero su contenido de gestión permite su desplazamiento casi completo al bloque funcional de gobierno) más algunas letras del artículo 22.2 como son parte de la e) (disposición de gastos), de la f) (aprobación de formas gestión de servicios), la g) (aceptación de delegación de competencias de otras Administraciones Públicas), la h) (conflictos de competencias), la j) acciones administrativas y judiciales), y la I) (alteración de la calificación jurídica de bienes públicos). Finalmente, dentro de este bloque de gobierno y ejecución deben incluirse las competencias residuales que en principio no se atribuyan a uno o otro.

Este bloque ha de corresponder al complejo orgánico Alcalde/Comisión de Gobierno, pero la distribución interna de atribuciones dentro de este bloque requiere un apartado específico.

\section{EL ALCALDE Y LA COMISIÓN DE GOBIERNO ANTE LA FUNCIÓN DE GOBIERNO MUNICIPAL}

Como acaba de señalarse, el ordenamiento vigente, incluso tras la reforma de 1999, resulta defectuoso desde el punto de vista de los órganos ejecutivos del Ayuntamiento, porque la Comisión de Gobierno carece de perfiles funcionales propios. Esta carencia no deja de poseer rasgos positivos por su flexibilidad, pero al mismo tiempo queda en exceso al albur de los deseos y visiones de cada Alcalde. Parece por ello necesario que la reforma perfile con más cuidado la naturaleza funcional de la Comisión de Gobierno aclarando su carácter gubernativo, es decir, como órgano colegiado de gobierno y gestión del Ayuntamiento bajo la presidencia del Alcalde. Pero una vez que se proceda a esta depuración conceptual conviene delimitar el significado del continuum Alcalde/Comisión de Gobierno. Admitiendo que existe un bloque de gobierno y de ejecución, las funciones de este bloque ¿cómo deben repartirse en su seno? Dos son las opciones que emergen: 
a) reforzamiento del Alcalde: todas o casi todas las atribuciones con alcance gubernativo y ejecutivo se conferirían al Alcalde ex lege, quien luego podría distribuirlas y delegarlas bien en favor de la Comisión de Gobierno bien en favor de Concejales singulares. Este reforzamiento conllevaría atribuir también al Alcalde competencias normativas para organizar el bloque funcional que le corresponde;

b) reforzamiento de la Comisión de Gobierno: es el fenómeno simétrico a la anterior opción. Todas las funciones de gobierno y ejecución se residenciarían en la Comisión de Gobierno, de la que el Alcalde sería el presidente y correspondería a aquélla, y no a éste, la normativa de organización interna.

En una alternativa similar, la legislación italiana ha optado por reforzar el Consejo antes que al Alcalde. Por nuestra parte creemos que este modelo no deja de provocar equívocos porque se quedaría a medio camino entre el presidencialismo municipal y el asambleismo. En otras palabras: no parece operativo reforzar la legitimidad democrática del Alcalde para convertirlo en el presidente de un órgano colegiado aun cuando los miembros de éste sean designados por el propio Alcalde. En consecuencia, se debería organizar el bloque funcional de gobierno conforme a los siguientes principios:

a) la Comisión de Gobierno tendría una composición limitada de Concejales designados libremente por el Alcalde con una mera información a posteriori al Pleno; ción;

b) el Alcalde se reservaria la potestad normativa de organiza-

c) esta potestad abarcaría la definición de las competencias, el nombramiento y la participación en la Comisión de Gobierno de los Delegados;

d) todas las funciones de este bloque corresponderían al Alcalde con una previsión de posible delegación (pero no transferencia) a la Comisión de Gobierno o a los Concejales miembros de ésta.

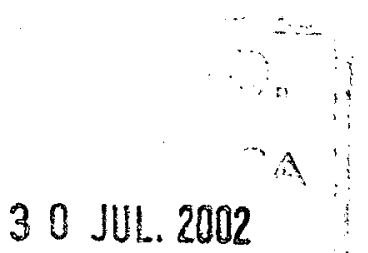




\section{EL CONTROL-SANCIÓN DEL ALCALDE Y LAS POSIBILIDADES DE UNA MOCIÓN DE CENSURA}

Para terminar este trabajo es preciso tocar el tema de la moción de censura. La nueva legislación italiana ha tratado el tema de una manera que entendemos poco satisfactoria, pues permite una moción de censura auténticamente "destructiva" que conlleva la disolución de la Corporación. Para nuestro ordenamiento hay que partir de la sustancia del cambio electoral que se propugna, es decir, la atribución al Alcalde de una legitimidad democrática directa $y$, por ende, autónoma del Pleno. A partir de aquí hay que señalar con rotundidad que la filosofía política que permite la elección directa del Alcalde se quebraría si se permitiese que un órgano que no lo eligió, el Pleno, pudiera cesarlo: en Estados Unidos y en Francia no existe moción de censura contra el Presidente aun cuando el impeachment pueda utilizarse torticeramente, como ocurrió con el Presidente Clinton. Entendemos por tanto que la elección directa del Alcalde enerva de radice cualquier posibilidad de moción de censura por el Pleno.

Pero esto no significa, sin embargo, que se deba renunciar a otros instrumentos de control de alta intensidad. Creemos que el principio de elección directa impide la moción de censura, pero al mismo tiempo no quebraría ese principio la regulación de una moción de reprobación de la Comisión de Gobierno con efectos declarativos no sancionadores. Cierto que la mayoría que se atribuiría al primer partido del municipio haría difícil esa moción, pero se alcanzarían dos fines: a) permitir que la oposición tenga la iniciativa en un debate de política general de carácter crítico para el Alcalde; b) disponer de un instrumento de reserva para el supuesto, no demasiado inhabitual, de un Alcalde que se distancia de su partido. Vistas así las cosas ¿por qué a la Comisión de Gobierno y no al Alcalde? Primero para que quede claro que la legitimidad del Alcalde es ajena al Pleno. Y segundo porque es a través de la Comisión como el Alcalde realiza las políticas objeto de la reprobación.

\section{CONCLUSIONES}

Primera. La Constitución, en su artículo 140 contempla la elección directa del Alcalde por los vecinos, correspondiendo al legislador ordinario establecer el sistema electoral sin más condicionantes que el sufragio sea universal, igual, libre, directo y secreto. 
Segunda. El cambio de legitimidad democrática del Alcalde requiere modular su posición en el seno del Ayuntamiento de manera que se deslinden dos bloques funcionales, uno de control y de impulso político y el segundo de gobierno, ejecución y gestión.

Tercera. El bloque funcional de control e impulso políticos ha de residenciarse en el Pleno, en tanto que el de gobierno, ejecución y gestión debe recaer en el continuum Alcalde/Comisión de Gobierno. Dentro de este continuum, sin embargo, debe corresponder al Alcalde la posición predominante de designar libremente a la Comisión y de asignarle normativamente sus atribuciones.

Cuarta. Para organizar esta nueva estructura municipal es necesario reformar el sistema electoral. Entre las diversas opciones que se plantean se puede defender el siguiente modelo:

1. elección a dos vueltas;

2. a la segunda vuelta sólo concurririan los dos candidatos más votados y se celebraría una semana después de la primera;

3. la votación para el Alcalde sería independiente de la de los Concejales y podría estar apoyado por todos los partidos, federaciones, coaliciones y agrupaciones que lo desearan;

4. para no "quemar" candidatos, el candidato a Alcalde podría encabezar también la candidatura de Concejales;

Quinta. Para reforzar la gobernabilidad del Ayuntamiento, la candidatura de Concejales más votada debería obtener el $60 \%$ de los puestos de Concejal. Como la Constitución no establece condicionantes en el sistema electoral municipal pero acentúa la función de gobierno de los Ayuntamientos, puede defenderse la constitucionalidad de esta fórmula, que no discrimina de entrada a ninguna candidatura.

Sexta. Por coherencia con la filosofía política ínsita en la elección directa del Alcalde, el Pleno no debe desposeer de su cargo al titular de un órgano que el Pleno no ha elegido. Pero es posible establecer mociones de reprobación a la Comisión de Gobierno con efectos políticos declarativos.

Séptima. Todos los cambios propugnados precisan exclusivamente la reforma de la LOREG y de la Ley Reguladora de las Bases del Régimen Local. 


\section{REFERENCIAS BIBLIOGRÁFICAS}

1. Para los antecedentes históricos de la figura del Alcalde en Derecho español sigue siendo útil la obra de Adolfo POSADA La evolución legislativa del Régimen Local en España 1812-1909 (1912), Instituto de Estudios de Administración Local, Madrid, 1982. Más reciente, conserva igualmente su valor el trabajo de Sebastián MARTín-RETORTILLO y Enrique ARGULLOL "Aproximación histórica al tema de la descentralización. 1812-1931", en Sebastián MARTíNRETORTILLO (dir.): Descentralización administrativa y organización política, Alfaguara, Madrid, 1973, t. I. Hay un buen tratamiento monográfico y sistemático de la evolución histórica de la figura del Alcalde en José I. MoRILLOVELARDE: El alcalde en la Administración española, Instituto García Oviedo, Sevilla, 1977. Para la posición del Alcalde en los primeros tiempos del constitucionalismo español véase Concepción de CASTRO: La Revolución Liberal y los municipios españoles (1812-1868), Alianza Ed., Madrid, 1979, así como Javier GARCÍA FERNÁNDEZ: El origen del municipio constitucional: autonomia y centralización en Francia y en España, Instituto de Estudios de Administración Local, Madrid, 1983. También es de interés la gran recopilación de Luis Cosculluela Montaner y Enrique Orduña Rebollo: Legislación sobre Administración Local 1900-1975, Instituto de Estudios de Administración Local, Madrid, 1981, 2 tomos.

2. Para una visión histórica general de la evolución del régimen local en Europa hay que manejar el libro de Luciano VANDELLI: EI Poder Local. Su origen en la Francia revolucionaria y su futuro en la Europa de las regiones (trad. P. Menéndez García y J. Suay Rincón), Instituto Nacional de Administración Pública, Madrid, 1992. Sobre la posición del Alcalde en el régimen local británico véase, como antecedente histórico, la compilación de documentos editada por W. THORNHILL: The Growth and Reform of English Local Government, Weidenfeld and Nicolson, London, 1971. La historia de la posición del Alcalde en Inglaterra se encuentra en Bryan KEITH-LuCAS y Peter G. RichaRds: Historia del Régimen Local Inglés en el Siglo XX (trad. J. Hernández Orozco), Instituto de Estudios de Administración Local, Madrid, 1980. Sobre el Alcalde en el actual régimen local británico, véase, en castellano, Luciano PAREJo: Derecho básico de la Administración Local, Ariel, BarceIona, 1988, págs. 259-277, así como el artículo de Antonio JiMÉNEZ-BLANCo "La organización local inglesa", en Documentación Administrativa, núm. 228, octubre-diciembre 1991 (monográfico sobre La organización municipan, págs. 217-224. Finalmente, uno de los trabajos más recientes que se han publicado, pero en lengua italiana, es el de Silvio Trollo: /l Local Government britannico. L'ente locale tra reppresentanza della comunità e ammninistrazione dei servici pubblici, Cedam, Padova, 1997.

La figura del Alcalde en el municipio alemán tiene un buen tratamiento histórico en Ramón MARTín MATEO: El municipio y el Estado en el Derecho alemán, Ministerio de la Gobernación, Madrid, 1965. En lengua castellana sigue siendo muy valioso el gran libro de Otto GönNENWEIN: Derecho municipal alemán (trad. M. Sáenz-Sagaseta), Instituto de Estudios de Administración Local, Madrid, 1967. También en castellano, pero de publicación más reciente, Luciano PAREJo: op. cit., págs. 213-233; y Santiago GonZÁLEZ-VARAS 
IBÁÑEZ: "La organización municipal en Alemania", en Documentación Administrativa, núm. 228, octubre-diciembre 1991 (monográfico cit.), págs. 257277. Las diversas categorías de los Alcaldes en Estados Unidos están bien descritas en la obra de George S. BLAIR: El gobierno local en los Estados Unidos (trad. L. E. Pellegrino), Bibliográfica Omeba, Buenos Aires, 1966, así como, más reciente, en el libro de materiales de Jefferson B. FordHAM: Local Government Law, The Foundation Press, Mineola, N. Y., 1986, 2. a ed. Hay referencias muy interesantes a la elección y actuación del Alcalde desde un punto de vista empírico-politológico en el clásico trabajo de Robert A. DAHL: Who governs? Democracy and Power in an American City, Yale University Press, New Haven, Conn., 1961. Aunque antiguo, hay que seguir citando la excelente síntesis de Enzo BALBONI «Problemi attuali del governo locale negli Stati Uniti d'American, en Paolo BiscareTti DI Ruffia (ed.): Problemi attuali del governo locale in alcuni Stati occidentali, Giuffrè, Milano, 1977 , págs. 463-608.

La referencia al Alcalde en Francia ha de comenzar necesariamente por dos clásicos. En primer lugar, Pierre-Paul-Nicolas HeNRION DE PENSEY: Del poder municipal y de la policía interior de los municipios (1820) (trad. J. Garcia Fernández), Instituto Nacional de Administración Pública, Madrid, 1990. Y tras Henrion de Pansey, M. de BARANTE: Des communes et de l'aristocratie, Librairie Française de Ladvocat,. Paris, 1821. La evolución histórica del Alcalde en el Derecho francés está bien estudiada en Maurice BouRJOL: La réforme municipale, Berger-Levrault, Paris, 1975, así como François BURDEAU: Liberté, libertés locales chéries, Cujas, Paris, 1994. Sobre lás últimas reformas municipales en Francia puede verse tanto a Pierre SUBRA DE BIEUSSES: "La administración municipal francesa", en Documentación Administrativa, núm. 228, octubre-diciembre 1991 (monográfico cit.), págs. 279-300, como Jean-François LACHAUME: L'administration communale, Librairie Générale de Droit et de Jurisprudence, Paris, 1994.

Para cualquier referencia sobre el Alcalde en el régimen local italiano hay que empezar a citar un clásico ya rebasado por los cambios legislativos: Luigi Giovenco y su L'ordinamento comunale, Giuffrè, Milano, 1974, 7. a ed., cuyo capítulo sobre el Alcalde era un modelo de claridad y de profundidad. La bibliografía abundante que trata de las reformas de 1990 y 1993 se puede compendiar en dos valiosos títulos: Pietro VIRGA: Diritto Amministrativo, vol. 3, Amministrazione locale, Giuffrè, Milano, 1994, 2. ed.; y Francesco StAderinI: Diritto degli Enti Locali, Cedam, Padova, 1998, 7. ed.; finalmente, sobre la posición política del Alcalde es imprescindible el ingenioso y vivido libro de Luciano VANDELLI: Sindici e miti. Sisifo, Tantalo e Damocle nell'amministrazione locale, II Mulino, Bologna, 1997. En lo que se refiere al Alcalde en Portugal hay que citar el artículo de Antonio CÁNDIDO DE OLIVEIRA "La organización municipal portuguesa: consolidación de la autonomían, en Documentación Administrativa, núm. 228, octubre-diciembre 1991 (monográfico cit.), págs. 225-256, que es una buena síntesis tanto de la historia municipal portuguesa como de su régimen vigente.

3. Para conocer los caracteres más sobresalientes de la actual política municipal española hay que advertir que nunca han abundado en España los trabajos que analicen el municipio desde una perspectiva política o al menos 
politológica, si bien desde finales de la década de los setenta ya aparecían algunos artículos en la Revista CEUMT de Barcelona. Afortunadamente, el Informe sobre el Gobierno Local que dirigió Tomás FONT I LLOVET (Ministerio para las Administraciones Públicas-Fundació Carles Pi i Sunyer d'Estudis Autonòmics i Locals, Madrid, 1992) propició una reflexión política y no sólo jurídica acerca de las Entidades Locales dando lugar a algunos trabajos de análisis más político de entre los que se pueden citar «El sistema político local: fórmulas de gobierno y participación ciudadana" de Miguel SÁNCHEZ MORón (págs. 289-321) y "Autonomía municipal y acción de gobierno" de Javier GARCIA FERNÁNDEZ (págs. 347-353). Después de esta Informe el propio TOmás FONT I LLOVET dirige desde 1995 el Anuario del Gobierno Local (Diputació de Barcelona-Marcial Pons) que contiene crónicas y artículos sobre el sistema político municipal. Hasta el presente han aparecido los tomos correspondientes a 1995, 1996, 1997, 1998 y 1999-2000.

4. Por el contrario, el análisis jurídico de las instituciones municipales, análisis que es presupuesto necesario para su reforma, es abundante y normalmente de gran calidad. Sin entrar en el tema más específico de la autonomía municipal, la organización municipal y, más concretamente, la posición jurídica del Alcalde y del Pleno, están bien tratados en Piedad GARCiA-EscuDERO Y Benigno PENDÁs: El nuevo régimen local español. Estudio sistemático de la Ley 7/1985, de 2 de abril, reguladora de las Bases del Régimen Local, Praxis, Barcelona, 1985, págs. 218-227; Francisco Sosa WAgner: Manual de Derecho local, Tecnos, Madrid, 1987, págs. 102-107; Luis MORELL OCAÑA: EI régimen local español, Civitas, Madrid, 1988, págs. 429-638; y Julio CASTELAO: Manual de Organización y Funcionamiento de las Entidades Locales, Ministerio para las Administraciones Públicas, Madrid, 1990. Además, en el cit. núm. 228 de Documentación Administrativa es preciso recordar los artículos de Luciano PAREJO "La potestad de autoorganización de la Administración Local» (págs. 13-43), de Luis ORTEGA "El Alcalde como elemento de la organización municipal» (págs. 45-60), de José Manuel CASTELLS "La Comisión de Gobierno" (págs. 61-80) y de Demetrio LOPERENA "El Pleno del Ayuntamiento" (págs. 81-112).

5. Sobre la capacidad del municipio para realizar políticas públicas es imprescindible el reciente libro coordinado por Quim Brugué y Ricard Gomà: Gobiernos locales y politicas públicas. Bienestar social, promoción económica y territorio, Ariel, Barcelona, 1998. Igualmente contiene un buen enfoque la también reciente obra coordinada por Tomás FONT I LLOVET: Dret local, Universidad Autónoma de Barcelona-Marcial Pons, Madrid, 1998, así como, los sucesivos volúmenes del citado Anuario del Gobierno Local que dirige el mismo Tomás FONT I LLOVET. En materia de políticas públicas locales hay que citar asimismo Luis Pablo Bourgon Tivao: Manual de Servicios Públicos Locales, Ministerio para las Administraciones Públicas, Madrid, 1991 y el trabajo dirigido por Juan Miguel de la CuÉtARA MARTínez: Introducción a los Servicios Locales. Tipos de prestación y modalidades de gestión, Instituto Nacional de Administración Pública, Madrid, 1991. Finalmente, sobre la relación del municipio con las Comunidades Autónomas y con la Unión Europea, véanse José EsTEVE PARDo: Organización supramunicipal y sistema de articulación entre Administración autonómica y orden local (La experien- 
cia de la RFA. Bases y perspectivas en España), Civitas-Diputació de Barcelona, Madrid, 1991; Laura CoLOMINAS I BASSOLS: La conflictivitat competencial. El règim local, Institut d'Estudis Autonòmics, Barcelona; 1991; así como los artículos correspondientes del Anuario del Gobierno Local cit. correspondientes a los años 1995 y 1996.

6. Sobre el sistema electoral local se debe recordar el vol. col. Local Elections in Europe, Institut de Ciències Politiques i Socials, Barcelona, 1994, que contiene, entre otros, dos trabajos referidos a España, ambos de carácter politológico: "Local elections in the Spanish political system: 1979-1991", de Lourdes LÓPEZ NIETO, $y$ "Local government in Catalonia: the making of a local elite, 1979-1991», de Joan Botella. Desde el punto de vista jurídico, además de los comentarios generales a la Ley Orgánica del Régimen Electoral General, véase José Antonio Alcón Zaragoza: Manual de Elecciones Locales, Ministerio para las Administraciones Públicas, Madrid, 1990, y Pablo SANTOLAYA: «El procedimiento electoral local» en el vol. col. Jornadas sobre elecciones locales, Instituto Nacional de Administración Pública, Madrid, 1999. 